\title{
A Financial Analysis of Certain Flexible Loans: Calculation of the Average Duration
}

\author{
Salvador Cruz Rambaud ${ }^{1}$ \\ ${ }^{1}$ Departamento de Economía y Empresa, University of Almería, Almería, Spain \\ Correspondence: Salvador Cruz Rambaud, Departamento de Economía y Empresa, University of Almería, La \\ Cañada de San Urbano, s/n, Almería, 04120, Spain. Tel: 34-95-001-5184. E-mail: scruz@ual.es
}

Received: December 18, 2012

Accepted: February 6, 2013

Online Published: March 18, 2013

doi:10.5539/ijef.v5n4p53

URL: http://dx.doi.org/10.5539/ijef.v5n4p53

\begin{abstract}
The current economic and financial crisis situation, in general, and the real-estate crisis, in particular, have favoured the introduction of new banking products, especially loans, which, on the one hand, try to make the investment in housing attractive through novel mortgage loans and, on the other hand, to adapt to the possible financial difficulties of the borrower. In effect, lot of families need to have a house, but the banks are afraid that the borrower punctually could not face the corresponding payments. In this case, some financial entities give the borrower the possibility of deferring some payments until the end of the loan term, under the conditions which will be detailed hereinafter. In this paper, we present a mathematical expression of the average duration of the loan and the value of the payment that would amortize the loan in the initially stipulated period.
\end{abstract}

Keywords: loan, mortgage, payment, deferred annuities, average duration

\section{Introduction}

The framework of this paper is the current situation of uncertainty in the financial markets and the labour instability and precariousness present in our modern society. In this context, we will focus on loans and, more concretely, on mortgage loans, where the borrower can have serious problems to repay some loan annuities. Thus, in order to try to partially solve this uncertainty (derived from the labour market), some loans have arisen in the banking market giving the borrower the possibility of deferring the payment of a part of his/her debt to a later period at the end of the transaction. In any case, it is necessary to clarify that this is not a debt condonation but a postponement in the payment of the debt. All this is independent of the principal amortization method (Ferruz, 1994) which can be any of the classic methods of loans amortization (French method, constant principal repaid method, American method, etc.).

In effect, in the financial market, when contracting a mortgage loan (Van Horne, 1997; Brealey and Myers, 2002; Brealey et al., 2004), there exist lot of possibilities of choosing several banking products whose underlying amortization methods are the classic ones, among them we can mention the French method (equal payments over the term: the most usual), the constant principal repaid method and the American method (Ayres, 1963). Even within these methods of amortization, some other financial characteristics can be considered, such as the interest-only loan and fixed or variable interest rates (Cruz and Valls, 2003).

On the other hand, we observe as, recently, credit institutions have started to offer, among their products, other modalities of mortgage loans, named, in general, flexible loans, since they offer to the borrower the possibility of choosing the amount or the instant of payment of some loan parameters. Within this new type of loan, it is necessary to mention the different mortgage loans offered by the Spanish banking:

- the first one gives the borrower the possibility of choosing the payment per year, increasing or reducing the loan duration, and

- the second one provides the borrower the possibility of paying at least ten times per year, since he/she can defer the payment of up to two payments.

In effect, one of the modalities of flexible loans (offered by the BBVA bank) is that in which the borrower can choose the postponement of up to two monthly payments, with the additional interest, in each of the years of the loan interval. Said in another way, the borrower can choose the payment of 10,11 or even 12 monthly payments per year. In general, in this type of loan, there exists an upper bound for the total number of deferred payments. 
Obviously, in case of no interest charges for the deferred payments, the most favourable choice for the borrower consists of postponing the delivery of the first two monthly payments of every year. We insist that this option implies a postponement and not a cancelation of the debt by the bank. There is not doubt that we are in presence of a random financial transaction (Gil and Gil, 1987; Gil Peláez, 1992) in which the monthly payments are variables characterized because the maturities are certain and the amounts are random (Suárez, 1991).

De Pablo (1991 and 1998) has been one of the first scholars in introducing the flexibility in the analysis of loans having tried to correct the amount of the payments according the rate of inflation of each period. From another point of view, Cruz et al. (1996) have applied the former methodology to loans applied to the Agricultural Sector. Later, García et al. (2001) proposed a novel amortization method based on annuities according to the cash-flows expected by the investment to which the loan was applied.

Despite the wide offer described in the former paragraph, there exist other possibilities of mortgage loans amortization that have not been defined yet and that can result very interesting, due to their flexibility, depending on the economic situation of the borrower.

This paper is organized as follows. Section 2 analyzes the real case proposed by the flexible loans described in this Introduction. Later, we determine the average duration of this type of loan and introduce the expression of the payment that would amortize the loan within the term initially proposed by the bank, taking into account the expected number of payments that the borrower would postpone. In Section 3, we solve the general case in which the borrower can defer up to $p$ payments within the same year, without any limit of postponements through the total term of $n$ years (loan duration), except the trivial limit $p \cdot n$. Section 4 solves the problem proposed in the two former sections in the case of a restriction on the total number, $m$, of deferred payments (of course $m<p \cdot n$ holds). Finally, Section 5 summarizes and concludes.

\section{Flexible Loans without Any Limit on the Payments Postponement}

Let us consider a flexible loan in which the borrower can defer up to two monthly payments within the same year. The payment of the deferred monthly amounts would take place immediately after finishing the loan, more postponements not being allowed. In this Section, we are going to assume that there is not a total limit on the number of deferred monthly payments or, what is the same, that this limit is $2 n$, being $n$ the number of years of the loan term.

A first solution to this problem consists in calculating the expected number of unpaid monthly payments and to repay all them at the end of the loan term with their respective accumulated interest charges. Nevertheless, we are interested in solving this problem keeping constant the payment during the loan duration and its extension.

To do this, we are going to calculate the present value of any combination of 10,11 or even 12 monthly payments which, with the same probability, the borrower can choose according his/her economic needs.

In effect, if $i$ is the effective annual interest rate to be applied to this financial transaction, $j_{(12)}$ is the nominal interest rate payable per months and $i_{(12)}$ is the equivalent monthly interest rate (Zima and Brown, 1988), tables 1 and 2 include, respectively:

- the discounted values of all possible choices of postponement of two monthly payments by the borrower, and

- the discounted values of all possible choices of postponement of one monthly payment by the borrower.

Table 1. Discounted values of the possible choices of postponement of two monthly payments

\begin{tabular}{llllll}
\hline Month & 1 & 2 & 3 & $\ldots$ & 12 \\
\hline 1 & - & $\left(1+i_{(12)}\right)^{-1}+\left(1+i_{(12)}\right)^{-2}$ & $\left(1+i_{(12)}\right)^{-1}+\left(1+i_{(12)}\right)^{-3}$ & $\ldots$ & $\left(1+i_{(12)}\right)^{-1}+\left(1+i_{(12)}\right)^{-12}$ \\
2 & - & - & $\left(1+i_{(12)}\right)^{-2}+\left(1+i_{(12)}\right)^{-3}$ & $\ldots$ & $\left(1+i_{(12)}\right)^{-2}+\left(1+i_{(12)}\right)^{-12}$ \\
3 & - & - & - & $\ldots$ & $\left(1+i_{(12)}\right)^{-3}+\left(1+i_{(12)}\right)^{-12}$ \\
$\vdots$ & $\vdots$ & $\vdots$ & $\vdots$ & $\ddots$ & $\vdots$ \\
12 & - & - & - & - & - \\
\hline
\end{tabular}

Table 2. Discounted values of the possible choices of postponement of one monthly payment

\begin{tabular}{llllll}
\hline Month & 1 & 2 & 3 & $\ldots$ & 12 \\
\hline Present value & $\left(1+i_{(12)}\right)^{-1}$ & $\left(1+i_{(12)}\right)^{-2}$ & $\left(1+i_{(12)}\right)^{-3}$ & $\ldots$ & $\left(1+i_{(12)}\right)^{-12}$ \\
\hline
\end{tabular}

Next, we will calculate: 
- the expected present value of all possible monthly rents where two payments have been deferred by the borrower,

- the expected present value of all possible monthly rents where one payment has been postponed by the borrower, and

- the present value when the borrower satisfies all monthly payments.

All this will be made under the assumption that all described cases have the same probability:

$$
p=\frac{1}{\left(\begin{array}{c}
12 \\
2
\end{array}\right)+\left(\begin{array}{c}
12 \\
1
\end{array}\right)+\left(\begin{array}{c}
12 \\
0
\end{array}\right)}=\frac{1}{79}
$$

Firstly, let us calculate the expected present value of all possible monthly rents (Bodie and Merton, 2000) where two payments have been deferred by the borrower $\left(V_{0}^{(1)}\right)$, assuming that the constant monthly payment to be satisfied within the same year is $m$ :

$$
\begin{aligned}
& V_{0}^{(1)}=\frac{1}{79} m \sum_{\substack{r, s=1 \\
r>s}}^{12}\left\{a_{\left.\overline{12}\right|_{i(12)}}-\left[\left(1+i_{(12)}\right)^{-r}+\left(1+i_{(12)}\right)^{-s}\right]\right\}= \\
& =\frac{1}{79} m\left\{\sum_{\substack{r, s=1 \\
r>s}}^{12} a_{\left.\overline{12}\right|_{i(12)}}-\frac{\sum_{r, s=1}^{12}\left(1+i_{(12)}\right)^{-r}+\sum_{r, s=1}^{12}\left(1+i_{(12)}\right)^{-s}}{2}+\frac{\sum_{h=1}^{12}\left[\left(1+i_{(12)}\right)^{-h}+\left(1+i_{(12)}\right)^{-h}\right]}{2}\right\}=
\end{aligned}
$$

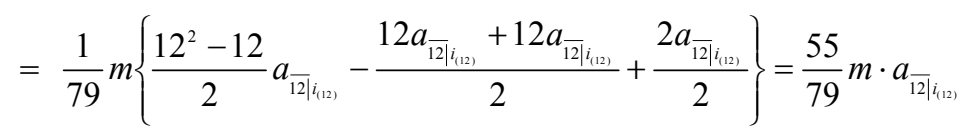

Secondly, let us calculate the expected present value of all possible monthly rents where one payment has been deferred by the borrower $\left(V_{0}^{(2)}\right)$, assuming, the same as the former paragraph, that the constant monthly payment to be satisfied within the same year is $m$ :

$$
V_{0}^{(2)}=\frac{1}{79} m \sum_{r=1}^{12}\left\{a_{\left.\overline{12}\right|_{(12)}}-\left(1+i_{(12)}\right)^{-r}\right\}=\frac{1}{79} m\left\{12 a_{\left.\overline{12 \mid}\right|_{(12)}}-a_{\left.\overline{12}\right|_{i_{(12)}}}\right\}=\frac{11}{79} m \cdot a_{\left.\overline{12}\right|_{(12)}}
$$

Finally, the present value when the borrower satisfies all monthly payments $\left(V_{0}^{(3)}\right)$ is:

$$
V_{0}^{(3)}=\frac{1}{79} m \cdot a_{\left.\overline{12}\right|_{(12)}}
$$

Therefore, the expected present $\left(V_{0}\right)$ of all possible modes of payment would be:

$$
V_{0}=V_{0}^{(1)}+V_{0}^{(2)}+V_{0}^{(3)}=\frac{67}{79} m \cdot a_{\left.\overline{12 \mid}\right|_{(12)}}
$$

By considering that the loan term is 15 years, the expected present value would be:

$$
V_{0}=\frac{67}{79} m \cdot a_{\overline{12 \mid i_{(12)}}} \cdot \ddot{a}_{1 \overline{15} i}=\frac{67}{79} m \cdot s_{\overline{12||_{(12)}}} \cdot a_{\overline{15} \mid i}=\frac{67}{79} m \cdot a_{15 \mid i}^{(12)}
$$

\subsection{Analysis of the Average Duration of a Flexible Loan}

A question derived from the analysis of flexible loans is the calculation of the average duration, $d$, that arises in this random financial transaction. If we consider that, in the period of extension to repay the outstanding monthly payments, the borrower continues having the possibility to defer the payment of 0,1 or 2 monthly payments, we would propose the following equation:

$$
\frac{67}{79} m \cdot a_{\left.\overline{12 \mid}\right|_{(12)}} \cdot \ddot{a}_{\bar{d} \mid i}=C_{0}=m \cdot a_{\overline{12}||_{(12)}} \cdot \ddot{a}_{\bar{n} \mid i}
$$

from where, by simplifying: 


$$
\ddot{a}_{\bar{d} \mid i}=\frac{79}{67} \ddot{a}_{\bar{n} \mid i}
$$

But, taking into account that the function $\ddot{a}_{\vec{x} \mid i}$ is increasing with respect to $x$, it can be stated that $d>n$. More specifically,

$$
d=-\frac{\ln \left(1-\frac{79}{67} i \cdot a_{\bar{n} \mid i}\right)}{\ln (1+i)}
$$

or:

$$
d=-\frac{\ln \left[\frac{79}{67}(1+i)^{-n}-\frac{12}{67}\right]}{\ln (1+i)}
$$

Graphically:

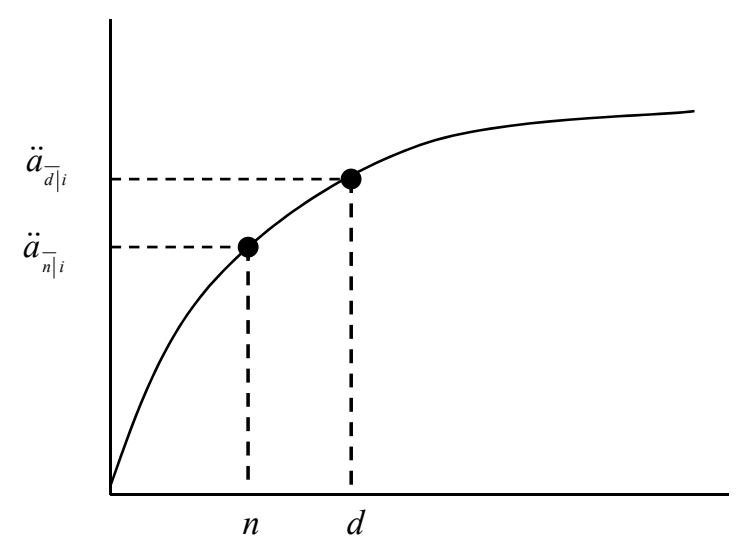

Figure 1. Present value of a unitary rent payable at the beginning of each period

\subsubsection{Example}

For a loan to be amortized in 10 years by the French method with constant monthly payments, $6 \%$ effective annual interest rate, an extension in the duration of something more than 2.5 years is expected; more specifically, 2.6212396 years.

In case that the borrower had to repay the deferred monthly payments consecutively when the initial term $n$ of the loan has finished, the extension $d$ of the loan would be evidently lesser. To do this, we would propose the following equation:

$$
\frac{67}{79} m \cdot a_{\left.\overline{12}\right|_{(12)}} \cdot \ddot{a}_{\bar{n} \mid i}+(1+i)^{-n} \cdot m \cdot a_{\left.\overline{12}\right|_{(12)}} \cdot \ddot{a}_{\bar{d} \mid i}=C_{0}=m \cdot a_{\overline{12} \mid i_{(12)}} \cdot \ddot{a}_{\bar{n} \mid i}
$$

from where, by simplifying:

$$
\ddot{a}_{\bar{d} \mid i}=\frac{12}{79}(1+i)^{n} \ddot{a}_{\left.\bar{n}\right|_{i}}
$$

or, what is the same:

$$
a_{\bar{d} \mid i}=\frac{12}{79} s_{\bar{n} \mid i}
$$

Last equation allows us to obtain $d$ :

$$
d=-\frac{\ln \left[\frac{91}{79}-\frac{12}{79}(1+i)^{n}\right]}{\ln (1+i)}
$$




\subsubsection{Example}

In our case, for a loan to be amortized in 10 years by the French method with constant monthly payments, $6 \%$ annual effective interest rate, an extension in the duration of something more than 2 years is expected; more specifically, 2.19636353 years.

\subsection{Calculation of the New Payment Which Amortizes the Loan in the Initially Stipulated Term}

Another problem we can propose is the calculation of the monthly payment $m^{\prime}$ that would amortize the loan in the initially stipulated period. To do this, in the first case, we would propose the following equation:

$$
\frac{67}{79} m^{\prime} \cdot a_{\overline{12||_{(12)}}} \cdot \ddot{a}_{\bar{n} \mid i}=m \cdot a_{\overline{12 \mid i_{(12)}}} \cdot \ddot{a}_{\overline{n \mid} \mid i}
$$

from where, we can obviously deduce that:

$$
m^{\prime}=\frac{79}{67} m
$$

\subsubsection{Example}

In our case, if the principal of the mortgage is $\$ 150,000$, one has:

- $i_{(12)}=(1+0.06)^{1 / 12}-1=0.00486755$

- $m=\frac{150,000 \cdot 0.00486755}{1-1.00486755^{-180}}=\$ 1,252.94$

- $m^{\prime}=\frac{79}{67} 1,252.94=\$ 1,477.35$

\section{A Generalization of Flexible Loans}

The objective of this Section is to generalize the approach presented in Section 2 for which we will present two new concepts, their corresponding notations and their respective mathematical expressions. In effect, let us consider the general case in which:

- $n$ represents the total number of years of the loan term,

- $k$ represents the installment in the payments $(k=2$, in case of half-yearly payments; $k=4$, in case of quarterly payments; ...; $k=12$, in case of monthly payments),

- $p$ represents the maximum number of payments which can be deferred in every year. Obviously, $p \leq k$ holds, and

- $m$ represents the maximum number of payments which can be deferred in total, during the $n$ years of the loan term.

If we denote by $a_{\overline{n / k \mid} \mid}$ the sum of the present values of all the possible unitary rents payable at the end of each period with $n$ payments where $k$ of them are zero $(k \leq n)$, it is verified that:

Lemma 1. $a_{\overline{n / k \mid i}}=\left(\begin{array}{c}n-1 \\ k\end{array}\right) a_{\bar{n} \mid i}$.

Proof. It is obvious, taking into account that every unitary payment of the rent belongs to the $\left(\begin{array}{c}n-1 \\ k\end{array}\right)$ possible combinations of $k$ zeros taken among the $n-1$ possible allocations, without considering the position where the considered payment is located.

\subsection{Example}

If, as previously assumed, in one year there can be two deferred monthly payments, the sum of the present values of all possible unitary rents with 10 payments is:

$$
\left(\begin{array}{c}
12-1 \\
2
\end{array}\right) a_{\left.\overline{12}\right|_{i(12)}}=\left(\begin{array}{c}
11 \\
2
\end{array}\right) a_{\left.\overline{12 \mid}\right|_{(12)}}=55 a_{\left.\overline{12 \mid}\right|_{(12)}}
$$

Analogously, if a deferred monthly payment was allowed, the sum would be: 


$$
\left(\begin{array}{c}
12-1 \\
1
\end{array}\right) a_{\left.\overline{12}\right|_{(12)}}=\left(\begin{array}{c}
11 \\
1
\end{array}\right) a_{\left.\overline{12}\right|_{(12)}}=11 a_{\left.\overline{12}\right|_{i(12)}}
$$

Finally, there is a unique rent where there are no monthly deferred payments, whose present value is $a_{\left.\overline{12}\right|_{(12)}}$. Observe that the sum of the previous present values coincides with the result obtained in Section 2.

In general, the formula that gives us the expected present value of all rents in which $0,1,2, \ldots, p k$-th of year can be deferred within the $n$ years of the loan term, is:

$$
V_{0}=\frac{\left(\begin{array}{c}
k-1 \\
p
\end{array}\right)+\left(\begin{array}{c}
k-1 \\
p-1
\end{array}\right)+\left(\begin{array}{c}
k-1 \\
p-2
\end{array}\right)+\cdots+\left(\begin{array}{c}
k-1 \\
0
\end{array}\right)}{\left(\begin{array}{l}
k \\
p
\end{array}\right)+\left(\begin{array}{c}
k \\
p-1
\end{array}\right)+\left(\begin{array}{c}
k \\
p-2
\end{array}\right)+\cdots+\left(\begin{array}{l}
k \\
0
\end{array}\right)} a_{\bar{k} \mid \bar{i}_{(k)}} \cdot \ddot{a}_{\bar{n} \mid i}
$$

Observe that:

$$
V_{0}=\frac{\left(\begin{array}{c}
k-1 \\
p
\end{array}\right)+\left(\begin{array}{c}
k-1 \\
p-1
\end{array}\right)+\left(\begin{array}{c}
k-1 \\
p-2
\end{array}\right)+\cdots+\left(\begin{array}{c}
k-1 \\
0
\end{array}\right)}{\left(\begin{array}{c}
k \\
p
\end{array}\right)+\left(\begin{array}{c}
k \\
p-1
\end{array}\right)+\left(\begin{array}{c}
k \\
p-2
\end{array}\right)+\cdots+\left(\begin{array}{l}
k \\
0
\end{array}\right)} S_{\bar{k}||_{(k)}} \cdot a_{\bar{n} \mid i}
$$

or, what is the same:

$$
V_{0}=\frac{\left(\begin{array}{c}
k-1 \\
p
\end{array}\right)+\left(\begin{array}{c}
k-1 \\
p-1
\end{array}\right)+\left(\begin{array}{c}
k-1 \\
p-2
\end{array}\right)+\cdots+\left(\begin{array}{c}
k-1 \\
0
\end{array}\right)}{\left(\begin{array}{l}
k \\
p
\end{array}\right)+\left(\begin{array}{c}
k \\
p-1
\end{array}\right)+\left(\begin{array}{c}
k \\
p-2
\end{array}\right)+\cdots+\left(\begin{array}{l}
k \\
0
\end{array}\right)} a_{\bar{n} \mid i}^{(k)}
$$

\subsection{Example}

Observe that, in the case described in Section 2, the denominator in the fraction of the expected present value is:

$$
\left(\begin{array}{c}
12 \\
2
\end{array}\right)+\left(\begin{array}{c}
12 \\
1
\end{array}\right)+\left(\begin{array}{c}
12 \\
0
\end{array}\right)=66+12+1=79
$$

\section{Case in Which the Total Number of Postponements Is Bounded}

If we assume that the total number of possible postponements by the borrower is restricted to 10 payments during the whole loan term, the number of possible cases is:

$$
f=\sum_{r=0}^{5}\left(\begin{array}{c}
15 \\
r
\end{array}\right)\left(\begin{array}{c}
12 \\
2
\end{array}\right) \sum_{s=0}^{r}\left(\begin{array}{c}
10-2 r \\
s
\end{array}\right)\left(\begin{array}{c}
12 \\
1
\end{array}\right)^{s}
$$

This formula could be generalized to the case in which:

- $n$ represents the total number of years of the loan term,

- $k$ represents the installment in the payments ( $k=2$, in case of half-yearly payments; $k=4$, in case of quarterly payments; ...; $k=12$, in case of monthly payments),

- $p$ represents the maximum number of payments which can be deferred in every year. Obviously, $p \leq k$ holds, and

- $m$ represents the maximum number of payments which can be deferred in total, during the $n$ years of the loan term.

In this case, the number of possible postponements would be:

$$
\begin{gathered}
f=\sum_{r=0}^{\operatorname{int}(m / p)}\left(\begin{array}{l}
n \\
r
\end{array}\right)\left(\begin{array}{l}
k \\
p
\end{array}\right) \sum_{s=0}^{r \operatorname{in}((m-p r)(p-1))}\left(\begin{array}{c}
n-r \\
s
\end{array}\right)\left(\begin{array}{c}
k \\
p-1
\end{array}\right) \sum_{t=0}^{s} \operatorname{int((m-pr-(p-1)s)(p-2))}\left(\begin{array}{c}
n-r-s \\
t
\end{array}\right)\left(\begin{array}{c}
k \\
p-2
\end{array}\right)^{t} \cdots \\
\cdots \sum_{v=0}^{m-p r-(p-1) s-(p-2) t \cdots-2 u}\left(\begin{array}{c}
n-r-s-t-\cdots-u \\
v
\end{array}\right)\left(\begin{array}{c}
k \\
1
\end{array}\right)^{v}
\end{gathered}
$$


being $\operatorname{int}(x)$ the integer part of $x$. In what follows and taking into account that $f$ is a function of $n, k, m$ and $p$, it will be represented by $f(n, k, m, p)$.

On the other hand, if we denote by $\left(r_{1}, \alpha_{1} ; r_{2}, \alpha_{2} ; \ldots ; r_{k}, \alpha_{k}\right) a_{\bar{n} \mid i}$ the sum of the present values of all unitary rents of $r_{1}+r_{2}+\cdots+r_{k} \leq n$ payments payable at the end of each period and distributed into $n$ periods, it is verified that:

Lemma 2. $\left(r_{1}, \alpha_{1} ; r_{2}, \alpha_{2} ; \ldots ; r_{k}, \alpha_{k}\right) a_{\bar{n} \mid i}=$

$$
\begin{gathered}
{\left[\alpha_{1}\left(\begin{array}{c}
n-1 \\
r_{1}-1
\end{array}\right)\left(\begin{array}{c}
n-r_{1} \\
r_{2}
\end{array}\right) \ldots\left(\begin{array}{c}
n-r_{1}-\cdots-r_{k-1} \\
r_{k}
\end{array}\right)+\alpha_{2}\left(\begin{array}{c}
n-1 \\
r_{2}-1
\end{array}\right)\left(\begin{array}{c}
n-r_{2} \\
r_{3}
\end{array}\right) \ldots\left(\begin{array}{c}
n-r_{1}-\cdots-r_{k-1} \\
r_{k}
\end{array}\right)+\cdots\right.} \\
\left.\cdots+\alpha_{k}\left(\begin{array}{c}
n-1 \\
r_{k}-1
\end{array}\right)\left(\begin{array}{c}
n-r_{1} \\
r_{1}
\end{array}\right) \ldots\left(\begin{array}{c}
n-r_{1}-\cdots-r_{k-2} \\
r_{k-1}
\end{array}\right)\right] a_{\bar{n} \mid i} .
\end{gathered}
$$

Proof. It is obvious, taking into account that every payment $\alpha_{i}$ of the rent is located in

$$
\left(\begin{array}{c}
n-1 \\
r_{i}-1
\end{array}\right)\left(\begin{array}{c}
n-r_{i} \\
r_{1}
\end{array}\right) \cdots\left(\begin{array}{c}
n-r_{i}-r_{1}-\cdots-r_{i-2} \\
r_{i-1}
\end{array}\right)\left(\begin{array}{c}
n-r_{i}-r_{1}-\cdots-r_{i-1} \\
r_{i+1}
\end{array}\right) \cdots\left(\begin{array}{c}
n-r_{i}-r_{1}-\cdots-r_{k-2} \\
r_{k-1}
\end{array}\right)
$$

possible combinations of $r_{i}-1$ "spaces" taken among the $n-1$ possible remaining, without considering the space where the considered payment is located, multiplied by the number of all possible allocations of the remaining rent payments in the spaces which successively remain free and so on.

The following result shows that Lemma 1 can be obtained as a consequence of Lemma 2.

Corollary. $a_{\overline{n / k \mid} \mid}=\left(\begin{array}{c}n-1 \\ k\end{array}\right) a_{\bar{n} \mid i}$

Proof. In effect, it can be considered that:

$$
a_{\overline{n / k \mid} i}=(n-k, 1) a_{\overline{n \mid i}}=\left(\begin{array}{c}
n-1 \\
n-k-1
\end{array}\right) a_{\overline{n \mid i}}=\left(\begin{array}{c}
n-1 \\
k
\end{array}\right) a_{\overline{n \mid i}}
$$

Finally, taking into account the former results, the expected value of all possible combinations of the loan amortization by the borrower (of course in case of absence of a breach of contract by the borrower) is:

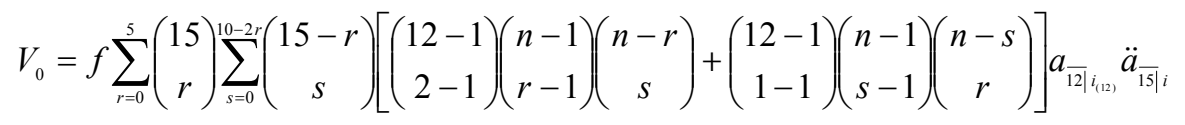

or, what is the same:

$$
V_{0}=f \sum_{r=0}^{5}\left(\begin{array}{c}
15 \\
r
\end{array}\right) \sum_{s=0}^{10-2 r}\left(\begin{array}{c}
15-r \\
s
\end{array}\right)\left[\left(\begin{array}{c}
12-1 \\
2-1
\end{array}\right)\left(\begin{array}{c}
n-1 \\
r-1
\end{array}\right)\left(\begin{array}{c}
n-r \\
s
\end{array}\right)+\left(\begin{array}{c}
12-1 \\
1-1
\end{array}\right)\left(\begin{array}{c}
n-1 \\
s-1
\end{array}\right)\left(\begin{array}{c}
n-s \\
r
\end{array}\right)\right] a_{\left.15\right|_{i} ^{(12)}}
$$

\section{Conclusion}

Nowadays, some Spanish banks (like the BBVA bank) are showing a certain flexibility and dynamism in adapting their offer of mortgage loans to the hard conditions that debtors have to support as a consequence of the economic and financial crisis. This uncertainty has implied that most of the loans, which only were random according to the interest rates, increase the uncertainty of other parameters characteristic of such financial transaction. This is the case of the loan presented in this paper. More specifically, the borrower has the option to defer the payment of 1 or 2 amounts until the end of the initially stipulated loan term, with a global maximum of deferred (not condoned) payments. Nevertheless, in this paper and due to methodological arguments, we have solved also the case in which this global limit does not exist. To solve these problems, we have employed the usual tools of Financial Mathematics and the Combinatorial Analysis, introducing two new concepts:

- the sum of the present values of all unitary rents payable at the end of each period with $n$ payments, where $k$ of them are zero $(k \leq n)$, denoted by $a_{\overline{n / k \mid i}}$, and

- the sum of the present values of all unitary rents payable at the end of each period with $r_{1}+r_{2}+\cdots+r_{k} \leq n$ payments distributed into $n$ periods, denoted by $\left(r_{1}, \alpha_{1} ; r_{2}, \alpha_{2} ; \ldots ; r_{k}, \alpha_{k}\right) a_{\bar{n} i_{i}}$. 
Lemmas 1 and 2 provide the mathematical expressions of these two present values, respectively, which help us to solve the problems presented in this paper. The following reseach we propose is the analysis of other flexible loans that are offered at present and even to propose other different loans which could be interesting in the current economic conjuncture.

\section{Acknowledgements}

This paper has been partially supported by the project "Valoración de proyectos gubernamentales a largo plazo: obtención de la tasa social de descuento", reference: P09-SEJ-05404, Proyectos de Excelencia de la Junta de Andalucía and Fondos FEDER.

\section{References}

Ayres, F. (1963). Mathematics of finance. New York: McGraw-Hill.

Bodie, Z., \& Merton, R. C. (2000). Finance. New Jersey: Prentice Hall.

Brealey, R., \& Myers, S. (2002). Principles of corporative finance. New York: McGraw-Hill.

Brealey, R., Myers, S., \& Marcus, A. (2004). Fundamentals of corporate finance. New York: McGraw-Hill.

Cruz Rambaud, S., \& Valls Martínez, M. C. (2003). Introducción a las matemáticas financieras. Madrid: Editorial Pirámide.

Cruz Rambaud, S., García Pérez, J., \& Andújar Rodríguez, A. S. (1996). Préstamos al sector agrícola: propuesta de un nuevo sistema de amortización. Revista Española de Economía Agraria, 175, 119-142.

De Pablo López, A. (1991). Préstamos de duración variable en función de las tasas de inflación. Cuadernos Aragoneses de Economía, 6, 83-92.

De Pablo López, A. (1998). Some factor for the correction of the inflation effect in financial transactions. Proceedings of the First Spanish-Italian Meeting on Financial Mathematics. Almería (Spain), 31-40.

Ferruz Agudo, L. (1994). Operaciones financieras. Descripción, análisis y valoración. Barcelona: Ed. Ariel S.A.

García Pérez, J., Cruz Rambaud, S., \& Andújar Rodríguez, A. S. (2001). Métodos de amortización de capital asociados a operaciones de inversión. Dirección y Organización, 25, 5-13.

Gil Luezas, M. A., \& Gil Peláez, L. (1987). Matemáticas de las operaciones financieras. Madrid: Universidad Nacional de Educación a Distancia.

Gil Peláez, L. (1992). Matemática de las operaciones financieras. Madrid: Editorial AC.

Information on mortgage loans BBVA. Retrieved from http://www.bbva.es

Suárez Suárez, A. S. (1991). Decisiones óptimas de inversión y financiación en la empresa. Madrid: Ediciones Pirámide, S.A.

Van Horne, J. (1997). Financial management and policy. New Jersey: Prentice-Hall.

Zima, P., \& Brown, R. L. (1988). Mathematics of finance (3rd ed.). New York: McGraw-Hill. 